\title{
Deformation and damage to buildings caused by ground movements in mining areas (case study)
}

\author{
Lucyna FLORKOWSKA*1, Izabela BRYT-NITARSKA ${ }^{1}$, and Janusz KRUCZKOWSKI ${ }^{1}$ \\ ${ }^{1}$ Strata Mechanics Research Institute of Polish Academy of Sciences, Cracow, Poland
}

\begin{abstract}
Human activity causes transformations in the near-surface layers of the rock mass, which result in long-term impacts on buildings and engineering infrastructure. Mining activities are particularly disadvantageous in this context, as they trigger severe deformation processes that reach the soil surface as a result of the excavation of deposits. The prevention of accidents and disasters caused by these impacts is based on knowledge derived from observation. Therefore, the aim of this study was to acquire and update knowledge on the impact of miningrelated ground deformation and tremors on buildings. The paper presents the results of measurements carried out on a group of buildings located in an underground mining area. The buildings have been affected by mining impacts since their construction in the 1980s. Despite the implementation of appropriate structural protection, the structures have been suffering deformation and damage. For the purposes of the study, two two-axis inclinometers were installed on the $15.2 \mathrm{~m}$ high bell tower, taking measurements at 6-hour intervals. Over a period of 10 months, changes in the leaning of the tower were measured and the condition of the other buildings observed. The study resulted in obtaining:

- values for the change in tilt of the two perpendicular walls of the tower (over a period of 10 months),

- correlation of the results with tremors measurements and periodic surveying measurements of the inclination of the vertical edge of the tower,

- image of damage to buildings caused by mining deformation of the ground.

On the basis of an analysis of the location and timing of minefields excavation, the occurrence of real ground movement in the mining areas, continuing even after the end of mining works, was confirmed and irregular deformation of the originally perpendicular walls of the masonry tower building was demonstrated. The tower did not behave as a rigid body; its horizontal profile was deformed.
\end{abstract}

Keywords: building damage, mining areas, subsoil deformations, tilt measurement anthropocene.

\section{Introduction}

The present epoch has been termed by scientists as the Anthropocene for a reason. Man-made activities are increasingly causing dynamic changes in geological structures. One of the areas in which the impact of human civilisation is particularly evident are issues related to the stability of the near-surface rock mass layers underlying buildings. The negative anthropogenic impacts include both the activation of natural geodynamic processes in landslide hazard areas $[2,4,6]$ and the induction of degradation and deformation processes in the rock mass. The cause of the most serious transformation of rock mass structures is mining activity and the mineral deposits' exploitation. In the areas affected by underground mining, which has been carried out for several years to several decades, the effects of mining of many fields and deposits are observed to overlap [3]. At the same time, long-lasting mining transformations may worsen the initially unfavourable geological conditions in the subsoil of a building, thus extending the duration of ground deformation. In the areas of highly developed agglomerations, surface deformations of a similar character (but of a much smaller scale) are caused by the construction of communication tunnels [11, 12].

The development of structural protection methods should be based on measurements and observations of the behaviour of structures subjected to such impacts. Traditionally, conventional and modern surveying methods are used to measure the deformation of buildings. Precise results of surveying observations (GNSS satellite measurements

*Corresponding author: E-mail address: florkowska@imgpan.pl (Lucyna FLORKOWSKA) 
(reference points), traversing (angular-linear measurements of the grid) and precision levelling) were achieved by the authors [6] when monitoring ground movement and building structures in the area of a moving landslide. In contrast, the authors [8] found that the use of GPS positioning to measure the displacement of building structures is burdened by standard deviations of $3.1 \mathrm{~mm}$ in the XX axis, $6.6 \mathrm{~mm}$ in the YY axis and $9.1 \mathrm{~mm}$ in the ZZ axis. It was thus shown that the characteristic errors of GPS observations are too large to apply this method with any real benefit in measuring building deformation.

Currently, laser scanning [11, 12] and photogrammetry [1] methods are being increasingly implemented for professional deformation measurements of building structures. Despite the enormous potential of the above methods, the challenge still standing in the way of their real-world engineering application is the excess of image data, the difficulty in establishing characteristic parameters and in automating anomaly detection. In the case of tunnel structures, an additional measurement challenge is the observation of the condition of not only the ground surface and buildings, but also the monitoring of the tunnel structure itself. The authors [9] achieved positive results using integrated laser scanning and photogrammetry methods. However, the level has still not been reached at which image perception methods can alone capture one or more metrics characterising the condition of a structure.

The dynamic development of coordinate non-contact motion analysis methods has led to attempts to use MCS (Motion Capture System) systems to monitor deformation in building structures. The authors [7] obtained evidence of the successful application of a motion capture system for tremors monitoring, for a three-storey experimental frame model. A system of markers attached to the target structure allows spatial measurement of movement with high accuracy and high sampling rate, suitable for monitoring free vibration of structures. Despite the advantages of MCS confirmed in laboratory conditions, it is rather difficult to imagine their wider use in real-world environments.

While surveying methods provide valuable data for scientific analysis aimed at developing forecasting and safety design methods, the periodic nature of the measurement sessions does not allow them to be used as safety monitoring systems. Real-time measurements of the structure's deformation state must employ devices allowing quasi-continuous data reading.

It should also be noted that in civil engineering issues, conducting in situ surveys and measurements is inherently associated with strongly localised initial conditions and an obvious lack of repeatability. In this context, case study analysis is an important research method [10]. They (case studies) bring real experimental value to science, while serving to develop methods for predicting impacts and designing structures properly.

\section{Methodology}

The methodology of this study was based on:

- locating the testing ground in an area repeatedly affected by mining exploitation so that the mining conditions are characteristic of mining areas where mining activities have continued for several decades;

- the choice of measuring equipment that allows quasi-continuous reading of the data,

- the proximity of the tremors monitoring station to take into account both static and dynamic mining impacts, which usually occur in tandem;

- the existence of surveying benchmarks, stabilised on the observed buildings, to provide data on the absolute displacements of the structures.

The testing ground was located in an area affected by static and dynamic mining impacts resulting from underground hard coal mining. After analysing the mining conditions, a set of buildings with previously noticed deformations was selected for observation. A preliminary inventory of the condition of the structures has been completed. Based on an analysis of the mining and structural conditions, a design for a measurement system was developed and installed on one of the buildings. The measurements, tailored to the structure type, took 10 months. During this time, periodic inspections were carried out in the other buildings with a photographic evidence of the damage areas. The obtained results were subjected to correlation analyses with the results of surveying measurements carried out by mine surveying services and with dynamic impact measurements made by the Upper Silesian Regional Seismological Network. An analysis of existing geologic documentation was included for the purposes of inference toward determining the causes of damage progression. 


\section{Case study}

\subsection{Description of structures}

The testing ground established for this study is located in the southern part of the Silesian Upland, in the area of the Rybnik Coal Basin. A group of buildings with relatively modern construction technology was selected for the study. It is a complex of religious buildings, erected between 1983 and 1987. The complex includes (Fig. 1):

A. a two-storey church segment with ground plan dimensions of $20.7 \times 24.0 \mathrm{~m}$, height $\max .21 .5 \mathrm{~m}$,

B. a religious education segment (currently housing a kindergarten), with ground plan dimensions of $10.8 \times 21.0 \mathrm{~m}$, two-storey, with a storey height of $3.3 \mathrm{~m}$,

C. a pastoral room segment, with ground plan dimensions of $7.2 \times 16.8 \mathrm{~m}$, two storeys, with a storey height of 3.3 $\mathrm{m}$,

D. a bell tower, with ground plan dimensions of $4.50 \times 4.7 \mathrm{~m}$ and height of $15.2 \mathrm{~m}$,

E. older rectory building.

A distinctive feature of the structure is its disjointed body in the plan (Fig. 2), which additionally includes different levels of foundations and different levels of ceilings and internal balconies of the church. The architecture of the roof slopes is also varied, having different inclinations: from flat roofs over segments $\mathrm{C}$ and $\mathrm{D}$, to the gabled roof of the church with angles of $33^{\circ}$ and $60^{\circ}$ The main segment $(\mathrm{A})$ has a basement floor with two floor levels (303.7 m above sea level and $304.3 \mathrm{~m}$ above sea level). Due to the planned risk of category III mining damage, the church was founded on a foundation base frame connected to a system of tie-beams. Underneath the benches, a slipping layer of one layer of unsanded felt is provided, laid on a $10 \mathrm{~cm}$ base of lean concrete. The load-bearing structure of the ground floor consists of reinforced concrete walls and columns, and the ceiling above the ground floor is a rib-and-slab structure. The load-bearing structure of the main floor of the church consists of reinforced concrete frames and purlins. All reinforced concrete elements were fabricated on site. The gable walls were designed as 51-cm-thick hollow brick, with vertical and horizontal reinforced concrete cores $27 \times 27 \mathrm{~cm}$ in cross-section, spaced every $2-3 \mathrm{~m}$. Above the window band, along the edge of the free wall, a $27 \times 27 \mathrm{~cm}$ reinforced concrete ring was designed. Within the segment, there are two, two-run staircases and one reinforced-concrete balancing run.

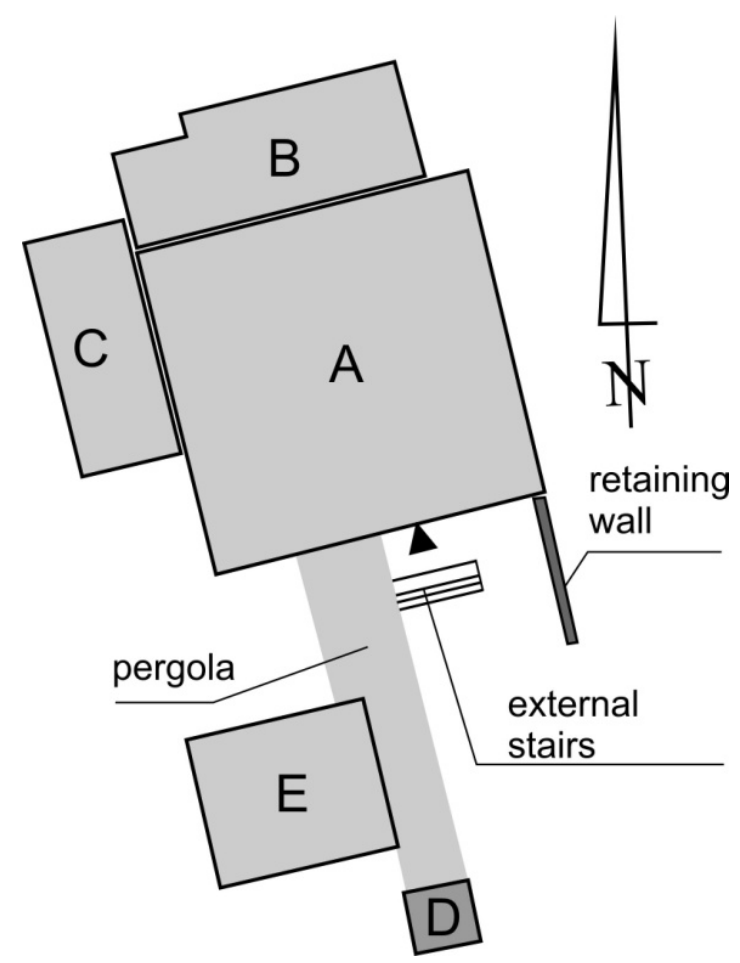

Figure 1. The building complex (description in the text) 


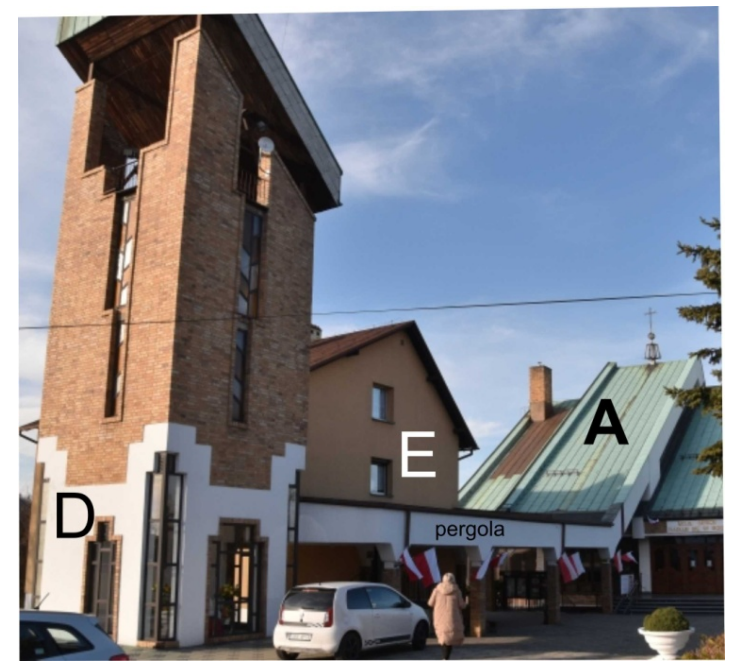

Figure 2. View of the church building and tower

Segments B and C are founded on a single level, both on bench frames braced by diagonal and transverse tie-beams, with a similar slip layer under the foundations as in segment A. The load-bearing structure of both segments consists of solid ceramic brick walls reinforced with reinforced concrete cores and reinforced concrete columns. The two storeys of segments $\mathrm{B}$ and $\mathrm{C}$ are covered with Ackerman ribbed ceilings, braced with reinforced concrete ring beams. The two-flight staircase is made of monolithic reinforced concrete.

Segments A, B, and C are separated by expansion joints with a design width of $15 \mathrm{~cm}$. Building D is a tower that serves as a bell tower. The foundation is designed as a slab foundation. The walls are reinforced concrete up to a height of $4.25 \mathrm{~m}$ and 39-cm-thick ceramic brickwork above. The vertical section of the building consists of three storeys with 18, 20, and $22 \mathrm{~cm}$-thick reinforced concrete ceilings. A two-flight monolithic reinforced concrete staircase leads from the entrance level (ground level) to the second floor. The other levels are climbed using a steel ladder. The manhole in the second ceiling measures $178 \times 90 \mathrm{~cm}$ and is located in the middle of the slab, while the manhole in the third/highest ceiling has a cross-section of $65 \times 65 \mathrm{~cm}$ and is located near the corner of the slab.

Additional bracing for the tower structure is provided by a steel frame, made of $150 \times 150 \times 15$ steel angles, spanning two storeys: from 4.25 to $10.30 \mathrm{~m}$ level. The sections are fixed to the tower walls with chemical anchors. The frame is braced by diagonal struts of $\phi 32 \mathrm{~mm}$ bars, tensioned using turnbuckles and nuts. The bracing structure was constructed in 2015 as a means of protecting the building from the effects of mining, after numerous cracks visible on the external and internal faces of the walls had been observed.

In addition to the main segments of the complex, important elements are the pergola - the canopy between the bell tower and the main entrance to the church, as well as the retaining wall and the external staircase. The load-bearing structure of the pergola consists of reinforced concrete columns and beams, founded on a grid of strip foundations and covered with a reinforced concrete ceiling of slab-and-rib construction. The retaining wall, located on the south side of the church, below the staircase to the main entrance, was constructed in 2015 as part of the repair of mining damage, after the first, damaged wall was demolished. The modern structure was made as a reinforced concrete element, in the form of monolithically joined $30 \mathrm{~cm}$-thick slabs, reinforced with $\phi 14 \mathrm{~mm}$ rods, founded directly on a bed of sand and gravel ballast and lean concrete.

\subsection{Mining conditions}

The building complex in question has been subjected to the effects of continuous underground coal mining. A map of the longwalls in operation between 2019 and 2021 in the vicinity of the structures is shown in Figure 3.

In the last decade, mining was carried out in the area of the church, using the longwall caving method, in seams: 703 - at a depth of $1,076 \div 1,087 \mathrm{~m}, 712$ - at a depth of $1,178 \div 1,201 \mathrm{~m}$ and 706 - at a depth of $1,123 \div 1,144 \mathrm{~m}$. The thickness of the extracted layer was: about $2 \mathrm{~m}$ for seam 703 , about $2.7 \div 3.8$ for seam 712 and about $1.5 \div 2.9 \mathrm{~m}$ for seam 706. Therefore, the area where the buildings were located was affected by both static and dynamic mining impacts. The distances of each wall from the church building are summarised in Table 1. 


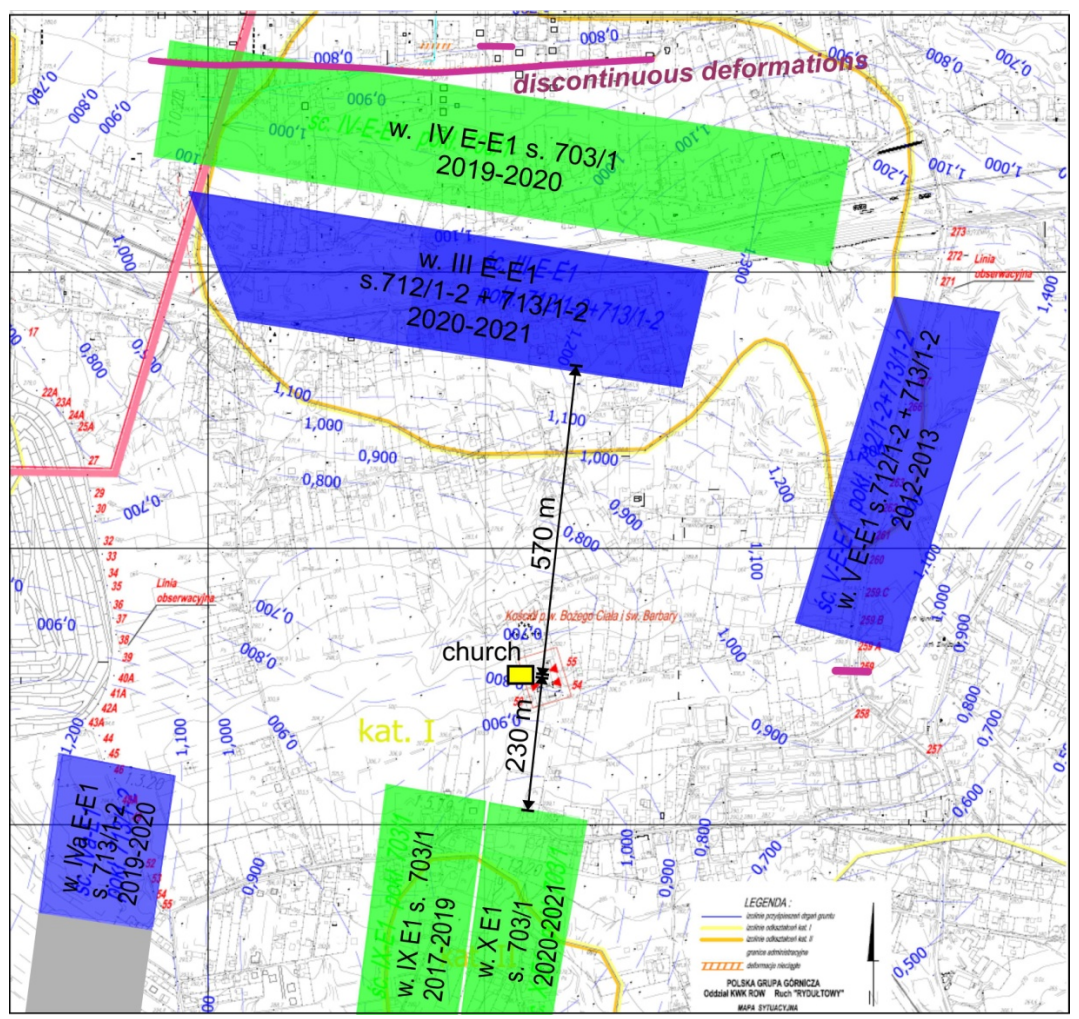

Figure 3. Coal deposits and walls that have been exploited in the vicinity of the analyzed objects in 2019-2020

Table 1. Coal deposits and walls that have been exploited in the vicinity of the analyzed objects

\begin{tabular}{|c|c|c|c|c|c|}
\hline \multirow{5}{*}{ seam } & wall & thickness $[\mathrm{m}]$ & depth $[\mathrm{m}]$ & distance $[\mathrm{m}]$ & service life \\
\hline \multirow{7}{*}{$703 / 1$} & VIIaE & 2.0 & 1,087 & 595 & $2010-2012$ \\
\cline { 2 - 6 } & VIIbE & 2.0 & 1,087 & 481 & $2013-2014$ \\
\cline { 2 - 6 } & VIIIE & 2.0 & 1,072 & 343 & $2015-2016$ \\
\cline { 2 - 6 } & IXE1 & 2.0 & 1,055 & 221 & $2017-2019$ \\
\cline { 2 - 6 } & XE1 & 2.1 & 1,048 & 206 & $2020-2021$ \\
\cline { 2 - 6 } & VEE1 & 2.3 & 1,055 & 381 & $2012-2013$ \\
\cline { 2 - 6 } & VIEE1 & 2.1 & 1,076 & 596 & $2014-2015$ \\
\hline \multirow{7}{*}{$713 / 12$} & IVaE1 & 2.7 & 1,178 & 686 & $2019-2020$ \\
\cline { 2 - 7 } & IEE1 & 3.8 & 1,176 & 176 & $2015-2016$ \\
\cline { 2 - 7 } & IIEE1 & 3.8 & 1,190 & 411 & $2017-2018$ \\
\cline { 2 - 6 } & IIIEE1 & 3.8 & 1,201 & 588 & $2020-2021$ \\
\hline \multirow{7}{*}{706} & IEE1 & 1.9 & 1,123 & 151 & $2011-2012$ \\
\cline { 2 - 6 } & IIEE1 & 1.5 & 1,138 & 382 & $2012-2014$ \\
\cline { 2 - 7 } & IIIEE1 & 1.5 & 1,144 & 626 & $2014-2016$ \\
\hline
\end{tabular}

During the measurement period, March to November 2021, the structures were theoretically not in the direct range of static impacts. 


\subsection{Measurement equipment}

In the tower building, measurement equipment has been installed consisting of two inclinometers manufactured by RST Instruments Ltd., mounted on mutually perpendicular walls: south and east. The sensor layout diagram and how the equipment is attached to the walls are shown in Figures 5 and 6 . The meter numbered 1230 was mounted to the east wall, while the meter numbered 1229 was mounted to the south wall. The equipment was installed inside the building. The mounting bracket, integrated with the equipment, was fixed to the bricks by steel mechanical anchors.

The height of the sensors, relative to ground level, is approximately $8 \mathrm{~m}$. The DTL202B (Biaxial Digital Tilt Loggers) meters used, using MEMS (Micro-Electro-Mechanical Systems) technology, allow tilt to be measured in two planes. The measuring range of the instruments is $\pm 15^{\circ}$, the resolution: $\pm 0.0006^{\circ}$, non-linearity $\pm 0.002^{\circ}$. The devices have $4 \mathrm{MB}$ built-in memory and a 5-year battery capacity; they allow operation with the RSTAR radio transmission system (distributed sensor topology) and the DT Link radio transmission system (sensor-hub topology). During the measurements, the instruments worked in a sensor-hub topology, with data from the inclinometer transmitted to a hub, and then via a USB connection to a computer. Once the system is up and running, measurement data can be read out remotely.

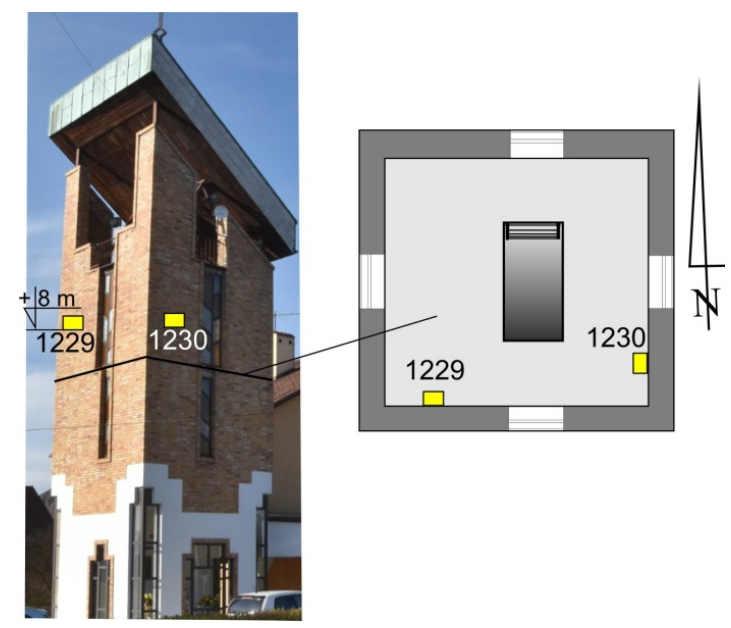

Figure 4. Coal deposits and walls that have been exploited in the vicinity of the analyzed objects in 2019-2020

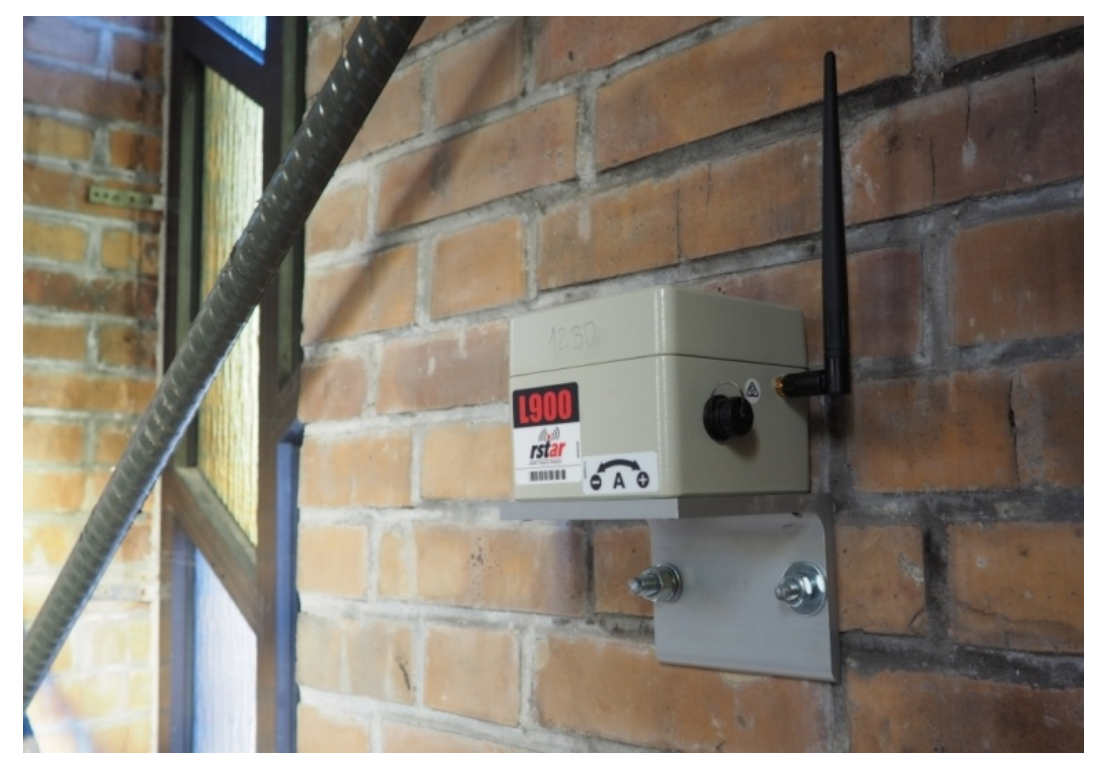

Figure 5. Coal deposits and walls that have been exploited in the vicinity of the analyzed objects in 2019-2020 


\section{Results}

\subsection{Changes in tower tilts}

The measurement system was deployed on 13 March 2021 and has been measuring tilts at a fixed frequency of 6 hours since that date. During the above interval, sensor 1229 recorded tilts of $0.40 \div 0.48^{\circ}$ in the plane of the south wall of the tower and $3.42 \div 3.47^{\circ}$ in the plane perpendicular to it. The 1230 sensor recorded tilts of $0.49 \div 0.52^{\circ}$ in the plane of the east wall and $0.26 \div 0.31^{\circ}$ in the plane perpendicular to the east wall.

It should be noted that the method used to mount the devices to the wall and the technology used to construct the building (brick wall) imply that the tilts registered by the sensors cannot be equated with the global tilting of the wall plane. Therefore, the changes in tilting were subjected to further analysis.

Figure 6 presents a diagram of the tilt variations in the N-S plane for the period from 13 March to 10 November 2021. The increment values were calculated by taking the 'zero' reading as a reference, after stabilization of the instrument:

$$
\Delta s=s_{0}-s_{n}
$$

where:

$s$ - is an increment of the tilting,

$s_{0}$ - is tilting on 14 March 2021,

$s_{n}-$ is current tilting.

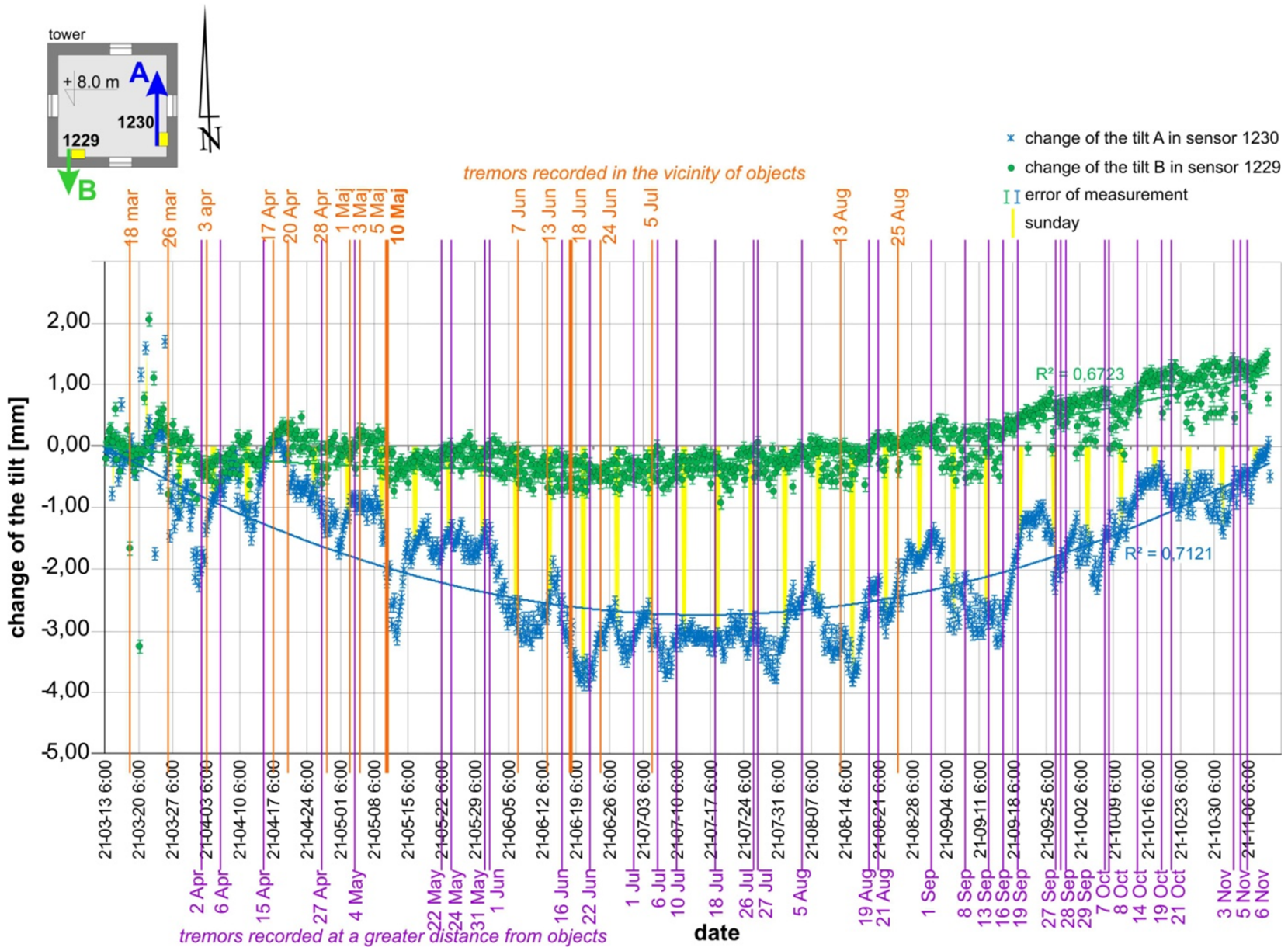

Figure 6. The graph of changes in the tilt of sensors in the N-S plane 
The changes recorded by sensor 1229, mounted on the south wall, are small and remain close to zero most of the time. A slight southward tilting of the sensor can be detected from mid-September onwards. In contrast, the 1230 gauge, attached to the eastern wall of the tower, recorded a few millimetres increase in the northward tilt, which increased non-linearly from March to June, then remained constant for about two months, after which it began to decrease. The graph shown in Figure 7 shows the consistent pattern of tilts of both gauges in the E-W plane, from 13 March to 7 June. This is followed by a tilt difference between the sensors, which is then maintained at around 2 mm. The nature of the tilt pattern is similar for both gauges: they tilt westwards, with the tilt increasing non-linearly from March to mid-June, then stabilising before decreasing from mid-August.

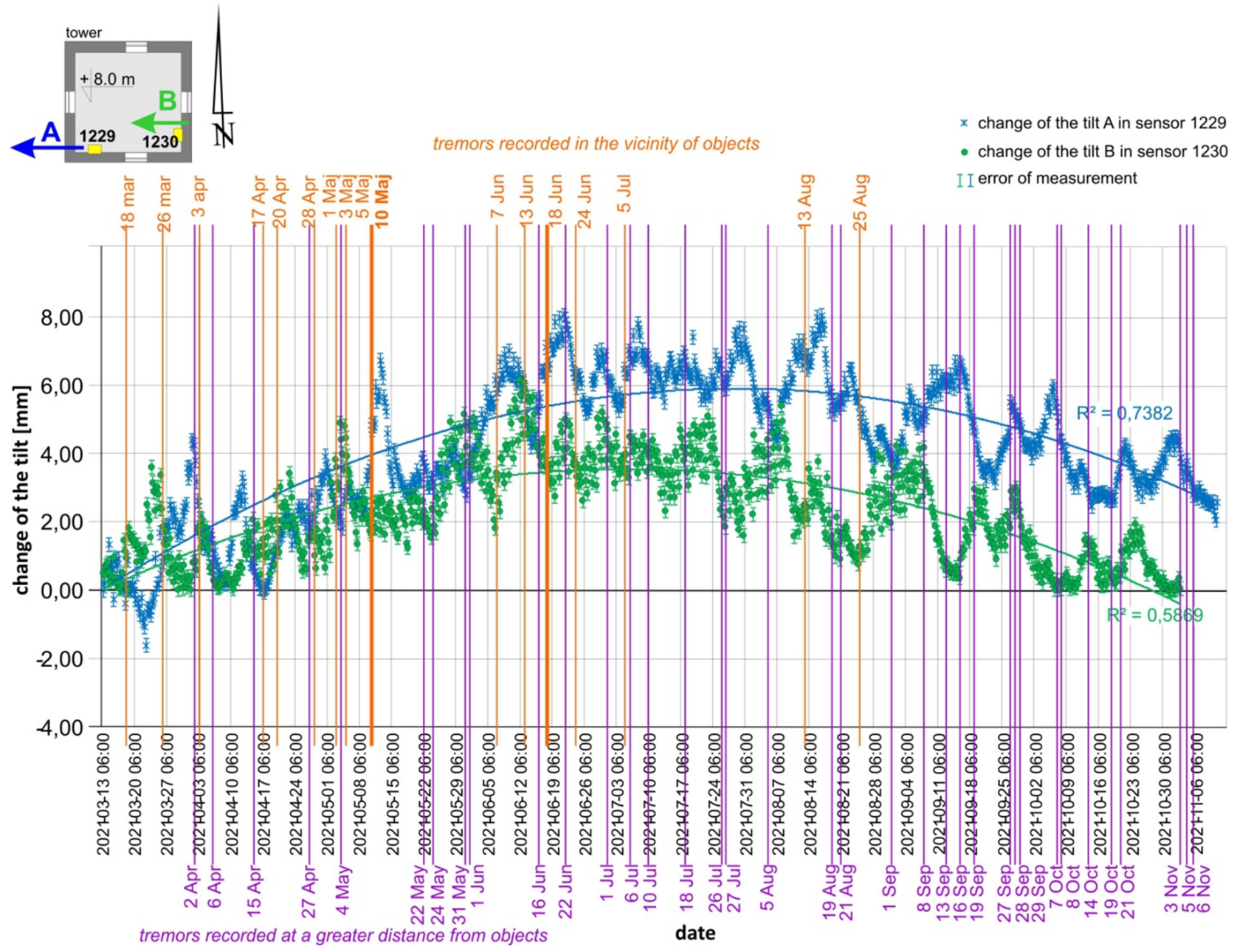

Figure 7. Graph of changes in the tilt of sensors in the E-W plane

The above pattern of tilts of the two sensors indicates that the main directions of the observed impacts do not coincide with the axes of the building plan, which causes twisting and turning of the cross-section of the tower. These directions changed during the observation period.

In both graphs, additional pronounced spikes appear on the leading line of the tilt change. They were explained by superimposing on the time axis the lines corresponding to the dates of the tremors recorded by the Upper Silesian Regional Seismological Network.

\subsection{Damage to buildings}

Based on periodic inspections of the structure of segments A, B, and C it was found that the building has a number of local damages, located mainly on the floor and walls, in places of expansion joints (Fig. 8). The nature and progression of the damage suggests that deformation is occurring in the subsoil, causing the structures to move northwards in line with the natural slope of the site. Despite the absence of any present mining works, damage propagation was noted 
during the observation period. Analysis of the existing technical documentation has shown that no comprehensive geological prospecting was carried out either at the design stage of the structures (1980s) or during the design of the new retaining wall (2015). Five test holes, $2.5 \mathrm{~m}$ deep, were excavated prior to the design of the complex. After exposing about $30 \mathrm{~cm}$ of soil layer, small loamy sands, sandy dusts, and dusts in semi-solid and hard-plastic state were observed. These soils may be prone to plasticising under the influence of rainwater. This was considered to be non-hazardous due to the absence of groundwater up to a level of $2.5 \mathrm{~m}$ and the natural slope of the site.

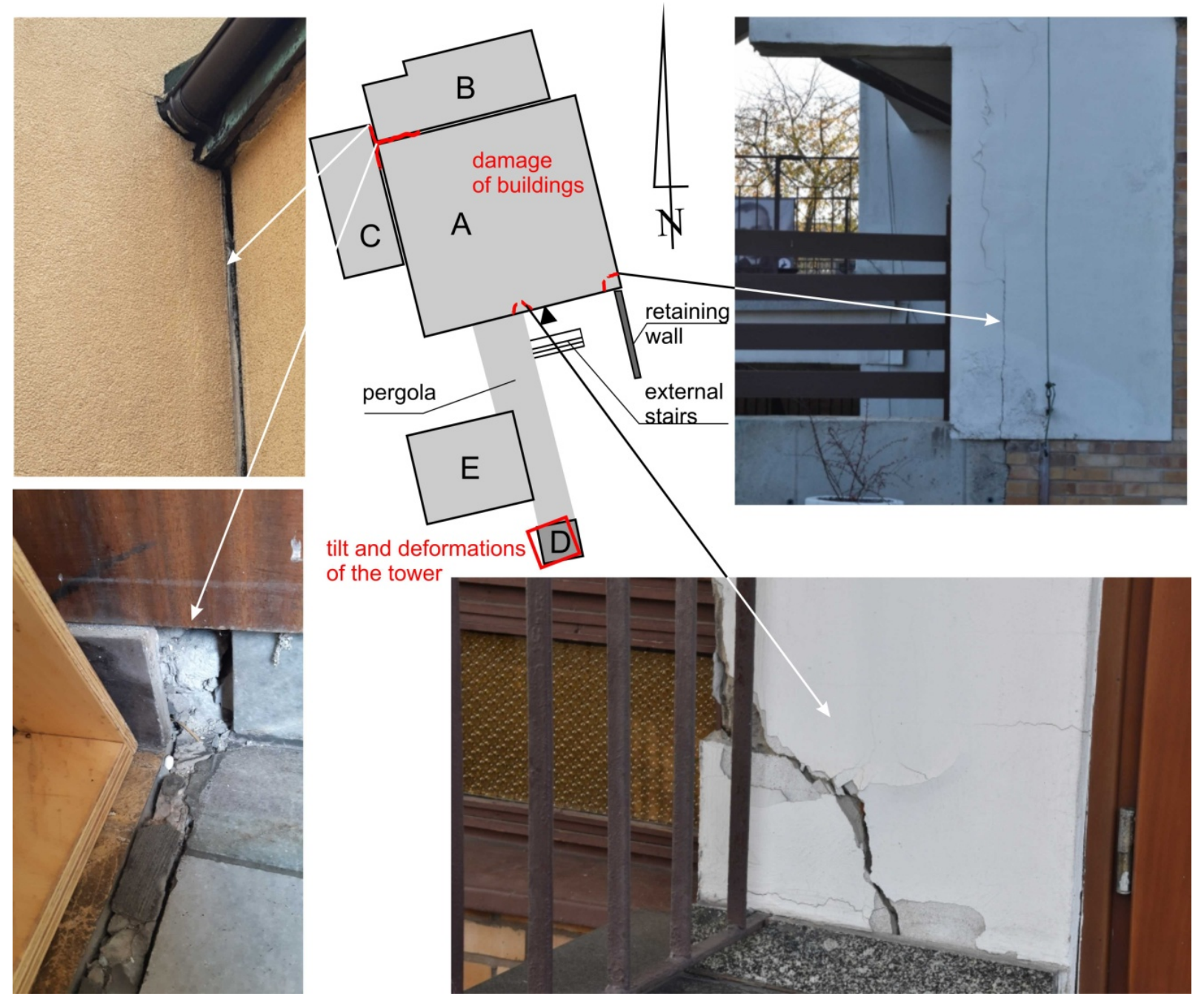

Figure 8. Damage and deformation observed in buildings

For the construction of the new retaining wall, two geotechnical boreholes were drilled $3 \mathrm{~m}$ deep. In both boreholes, under the layers of non-construction mounds, hard-plastic and plastic dusts were found. In the light of the deformation and damage to the objects, the existing survey should be regarded as inadequate. In order to clarify the causes of the observed processes, an in-depth geological assessment should be carried out, based on test holes located around the building complex, with particular emphasis on the northern side. Cores should be taken from the holes for laboratory testing. It is advisable to consider the use of one or two boreholes for the installation of inclinometer pipes and monitoring of ground deformation. The results of the geological prospecting and inclinometric measurements will also be used as the basis for developing a protection concept for the site.

\section{Discussion}

As already mentioned, the data obtained should be treated as a local value, assigned to the point of attachment of the meter. Although the tower structure is reinforced by a spatial steel frame, it cannot be assumed that it works as a rigid solid. This assumption is not confirmed by the discrepancy in the values and main directions of the 
measured deflections. Experience shows that the reasons for these discrepancies do not lie solely in the locality of the measurement, but are also due to the properties of slender masonry structures. Results obtained by the authors during measurements of a similar structure (bell tower) (Florkowska and Kanciruk [5], showed twisting of the structure in the horizontal plane. A similar behaviour was observed in the present study. The tower tilts towards the excavations closest to it, while undergoing a twist. In addition, it loses its rectangular cross-sectional shape.

\subsection{Analysis of tilt changes}

\subsubsection{Trend lines and global rates of change}

When considering the global lines of change, an increase in displacements is noticeable from the beginning of the measurements (March 2021) until July 2021, then a period of stabilisation occurred, followed by a decrease in tilts since August. The rate of tilt change varied over the measurement period. The smallest increases occurred in the month of July, while the maximum rates occurred in March and November and were about $2 \mathrm{~mm} / \mathrm{month}$.

\subsubsection{Local variations}

In addition to the clearly marked general line of change, there is a twofold systematic local variation in Figures 6 and 7:

- measurement errors, resulting from the instrument's inaccuracy $(0.104 \mathrm{~mm})$ and inaccuracies during assembly; in the range up to approx. $0.3 \mathrm{~mm}$,

- systematic changes, occurring on a daily and weekly basis, resulting from the frequency of use of the bell tower.

Due to its religious function, the structure is subject to the dynamic effects of the bells installed in the tower. On Sundays, when services are held, the bells are rung with the greatest frequency and the impacts transmitted by the structure are perceptible to the instruments. The bells are rung with less frequency on weekdays, but during the week there are additional services (e.g. funerals) outside the established order that involve the bells. They can cause additional local disturbances. Analysing the course of the graphs at short-period scales (daily and weekly), the value of local variability with technical-utility background was determined to be $0.8 \mathrm{~mm}$.

\subsubsection{Additional anomalies}

In addition to the local deviations from the trend line mentioned above, there are noticeable anomalies occurring irregularly, which cannot be explained by software. These are spikes, reaching a few millimetres within 1-2 days. They were explained by superimposing on the time axis the lines corresponding to the dates of the tremors recorded by the Upper Silesian Regional Seismological Network. They are the structure's response to dynamic actions transmitted from the foundation. The most intense change of this nature was recorded by the instruments on 10 May 2021 , corresponding to a tremor of $0.8066 \mathrm{~mm} / \mathrm{s} 2$ (Fig. 6 and 7 ).

\subsection{Reference to survey measurements}

\subsubsection{Church building subsidence}

The obtained results of the tilt measurements were additionally correlated with the results of the surveying measurements carried out by the mine's surveyors. Survey measurements of the height of the benchmarks, installed on segments A, B, and C, had been carried out since 2003. Initially, the heights of six benchmarks were measured: 54, $55,56,57,58$ and 59, as of 2015, only benchmarks 54, 55 and 59 remained (Fig. 9). The subsidence determined on this basis over an 18-year period is: $70.8 \mathrm{~cm}$ for benchmark 54, $72.6 \mathrm{~cm}$ for benchmark 55 and $73.2 \mathrm{~cm}$ for benchmark 59. It can be concluded that along the contour of the church plan the subsidence is almost uniform; the difference in subsidence between the south-west corner (59) and the south-east corner (54) is $2.4 \mathrm{~cm}$.

\subsubsection{Tower edge tilt}

Starting in 2019, surveys were made of the tilt of the south-west edge of the tower. The horizontal displacement of a point, located $8 \mathrm{~m}$ above ground level, was measured. The results obtained in the following measurement sessions, from February 2019 to November 2021, are shown in Fig. 10. From the data obtained, it was found that the magnitude of the tower tilt (at $8 \mathrm{~m}$ height) changed over 22 months from $11.7 \mathrm{~mm}$ to $29.5 \mathrm{~mm}$, which (assuming linearity) corresponds to a change from 1.5 to $3.7 \mathrm{~mm} / \mathrm{m}$. The difference in tilt between January and November 2021 (which 
roughly corresponds to the period of the measurements in question) is: $1 \mathrm{~mm}$ for the N-S component, $4 \mathrm{~mm}$ for the E-W component.

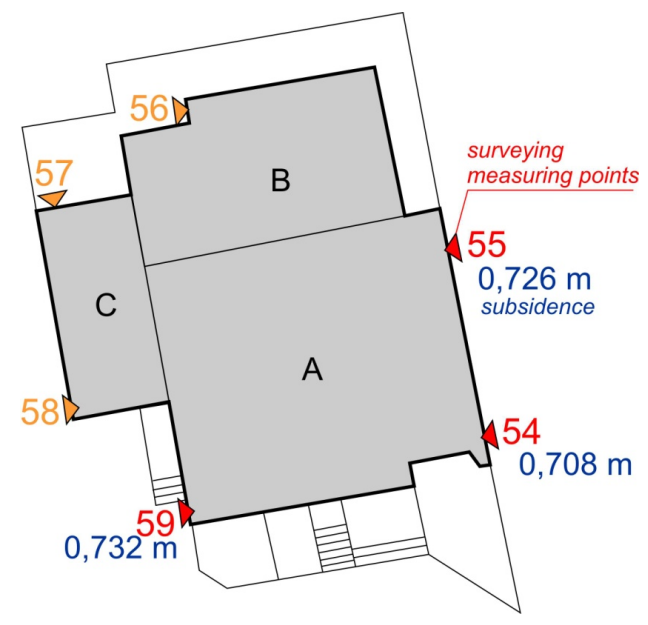

Figure 9. Subsidence of measurement points located on the church in the period 2003-2020

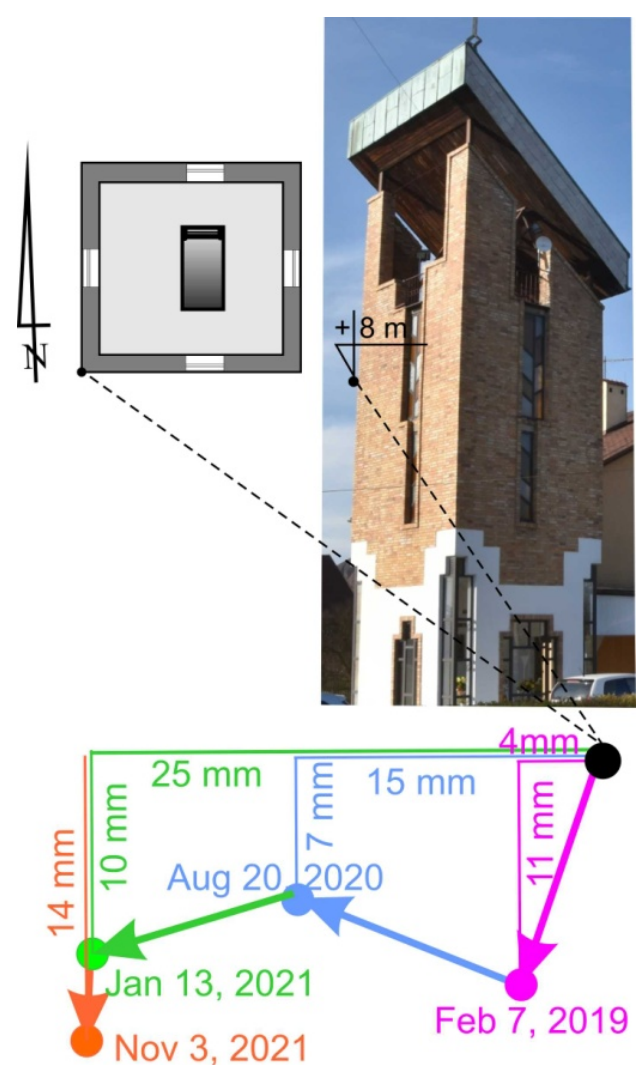

Figure 10. Results of surveying measurements of the tower tilt, made from Feb. 7, 2019 to Nov. 3, 2021

\section{Conclusions}

Although the methodology of scientific research, in general, considers the test and experimental methods more reliable (ensuring repeatability of conditions), there are areas of knowledge where the only real way of learning in situ is through the method of so-called case study analysis. These areas include the issue of the impact of ground deformation on building structures. The results of measurements and observations presented in this paper are a case study contributing to the knowledge of the impact of mining-induced ground deformation on existing buildings. 
The conclusions drawn from the study should be applied to freestanding buildings grouped in clusters, while the measurement results themselves should be applied to slender buildings with a small horizontal projection. Analysis of the results shows that in long-term mining areas, ground displacement is a process that lasts much longer than mining works. Buildings are subject to complex conditions of impact, both static and dynamic, which overlap each other.

Monitoring deformation changes with MEMS-type devices is a good method for continuous remote observation of the condition of structures. In the case of tower-shaped buildings, the tilt is a characteristic marker of the structural response. The DTL instruments used were found to have the sensitivity suitable for use in safety monitoring. Drawing on the experience gained, such a system should be based on multipoint measurement, placing sensors both around the perimeter of the floor plan and at several heights/floors. The research initiated will continue towards developing the launched measurement system into a wider monitoring network. The results obtained confirm the need to develop the adopted research direction and to extend the field measurement networks. This is important both in the context of the scientific study of anthropogenic processes in the subsoil, as well as in the applied dimension related to the safety of building structures.

\section{Acknowledgement}

The work was financed by the Ministry of Education and Science (Poland) as part of the research of Strata Mechanics Research Institute of Polish Academy of Sciences

\section{References}

1. Alhaddad, M., Dewhirst, M., Soga, K. \& Devriendt, M. A new photogrammetric system for high-precision monitoring of tunnel deformations. Proceedings of the Institution of Civil Engineers: Transport 172(2), 81-93 (2019).

2. Ciampalini, A. et al. Analysis of building deformation in landslide area using multisensor PSInSAR PM $^{\mathrm{TM}}$ technique. International Journal of Applied Earth Observation and Geoinformation 33, 166-180 (2014).

3. Florkowska, L. Land subsidence due to mining operations in disturbed rock mass, on the example of Ruda Sląska (Poland). Archives of mining sciences 55(3), 691-701 (2010).

4. Florkowska, L. The Application of Numerical Analysis in Determining the State of the Rock Mass Around Directional Wells in ISRM European Rock Mechanics Symposium - EUROCK 2017 (ed Konicek, P.) 191 (2017), 785-794.

5. Florkowska, L. \& Kanciruk, A. Analysis of the Consequences of Mining Exploitation in Substantially Disturbed Strata Based on Spatial Measurements of a Building's Tilt. in Rock mechanics for resources, energy and environment. Proceedings of Eurorock 2013 -the ISRM International Symposium Wrockaw, Poland, 23-26 September 2013. CRC Press. (2013), 575-580.

6. Florkowska, L., Bryt-Nitarska, I., Gawałkiewicz, R. \& Kruczkowski, J. Monitoring and Assessing the Dynamics of Building Deformation Changes in Landslide Areas. Buildings 10(1) (2020).

7. Park, H. S., Park, K., Kim, Y. \& Choi, S. W. Deformation Monitoring of a Building Structure Using a Motion Capture System. IEEE/ASME Transactions on Mechatronics 20(5), 2276-2284 (2015).

8. Seco, A., Tirapu, F., Ramírez, F., García, B. \& Cabrejas, J. Assessing building displacement with GPS. Building and Environment 42, 393-399. ISSN: 0360-1323 (2007).

9. Structure monitoring and deformation analysis of tunnel structure. Composite Structures 276, 114565. ISSN: 0263-8223 (2021).

10. Strzałkowski, P. Some Remarks on Impact of Mining Based on an Example of Building Deformation and Damage Caused by Mining in Conditions of Upper Silesian Coal Basin. Pure and Applied Geophysics volume 176, 25952605 (2019).

11. Sun, H. et al. Tunnel Monitoring and Measuring System Using Mobile Laser Scanning: Design and Deployment. Remote Sensing 12. ISSN: 2072-4292 (2020).

12. Xu, X., Yang, H. \& Kargoll, B. Robust and automatic modeling of tunnel structures based on terrestrial laser scanning measurement. International Journal of Distributed Sensor Networks 15, 1550147719884886 (2019). 